\title{
Burden of Crohn's disease: economics and quality of life aspects in Italy
}

This article was published in the following Dove Press journal:

ClinicoEconomics and Outcomes Research

23 July 2012

Number of times this article has been viewed

\author{
Viviano Benedini' \\ Nicola Caporaso ${ }^{2}$ \\ Gino Roberto Corazza ${ }^{3}$ \\ Zaccaria Rossi ${ }^{4}$ \\ Giovanni Fornaciari ${ }^{5}$ \\ Mario Cottone 6 \\ Giorgio Frosini ${ }^{7}$ \\ Mauro Caruggi ${ }^{8}$ \\ Chiara Ottolini ${ }^{8}$ \\ Giorgio L Colombo9,10 \\ On behalf of the COSMO \\ Study Group \\ 'Department of Gastroenterology, \\ AO Carlo Poma, Mantova; \\ ${ }^{2}$ Department of Gastroenterology, \\ University of Naples, Federico II, \\ Naples; ${ }^{3}$ IRCCS Policlinico San \\ Matteo, Pavia; ${ }^{4}$ Department of \\ Gastroenterology, Ospedale Regina \\ Apostolorum, Albano Laziale, Rome; \\ ${ }^{5}$ Department of Gastroenterology, \\ Arcispedale S Maria Nuova, Reggio \\ Emilia; ${ }^{6}$ Medical Division, Azienda \\ Ospedaliera Cervello, Palermo; \\ ${ }^{7}$ Department of Gastroenterology, \\ Policlinico Universitario Senese, Siena; \\ ${ }^{8}$ Hospital S Antonio Abate, Gallarate, \\ Varese, 'University of Pavia; School \\ of Pharmacy, Pavia, Lombardy; ${ }^{10}$ Studi \\ Analisi Valutazioni Economiche (SAVE), \\ Milan, Italy
}

Correspondence: Giorgio L Colombo Studi Analisi Valutazioni Economiche, Via Previati 74, Milan 20149, Italy

Tel +3902 485I 9230

$\mathrm{Fax}+390273960369$

Email giorgio.colombo@unipv.it
Background: This was a prospective observational study designed to evaluate direct and indirect costs and quality of life for patients with Crohn's disease in Italy from the perspectives of the National Health System and of society.

Methods: A total of 162 male and female subjects aged 18-70 years with Crohn's disease in the active phase and a Crohn's Disease Activity Index score $\geq 150$ were included in the study. Subjects were recruited from 25 Italian centers on a consecutive basis. The study consisted of four visits undertaken every 6 months with a follow-up period of 18 months. The study started on September 1, 2006 and was completed on April 12, 2010. Multivariate analyses were carried out on demographic characteristics, treatment costs based on the prescribed daily dose, resource use and other cost parameters, and changes in quality of life using the EQ5D questionnaire.

Results: Cost of illness per subject with Crohn's disease in Italy was estimated to be $€ 15,521$ per year, with direct costs representing $76 \%$ of total costs. Nonhealth care costs and loss of productivity accounted for $24 \%$ of total costs. Societal costs during the first months of enrolment were higher compared with costs in the final months of the study. Quality of life measured by the EQ-5D was 0.558 initially and then increased to 0.739 , with a mean value of 0.677 during the enrolment period. The cost of illness was not correlated with age or gender.

Conclusion: The cost of illness was correlated with quality of life; Crohn's disease had a negative impact on subjects' quality of life, and higher costs corresponded to a lower quality of life as measured with the EQ5D. Drug treatment may improve quality of life and reduce hospitalization costs. Our results appear to be in line with the results of other international cost-of-illness studies.

Keywords: Crohn's disease, quality of life, EuroQol, EQ5D, cost-of-illness, cost analysis, economic evaluation

\section{Introduction}

Crohn's disease is a chronic inflammatory condition that can involve any region of the gastrointestinal tract, from mouth to anus, but typically affects the distal small bowel, the terminal ileum (ileitis), and/or colon (colitis), or both (ileocolitis). Crohn's disease is reasonably common, affecting about 100,000 Italians and 2 million Americans. The annual incidence is around 3-4 new cases per 100,000. The peak age of disease onset is 20-25 years, but the disease can manifest itself at any age, from infancy to over 70 years of age, and affects males and females equally. Although the precise etiology of Crohn's disease is still unknown, it is thought that the disease is related to a rich diet in developed countries or to specific genetic characteristics. ${ }^{1}$ Smoking and oral contraceptives are possible risk factors. Some studies have shown that the disease may 
have a hereditary component, in that $15 \%-20 \%$ of individuals with Crohn's disease have one or more close relatives with either Crohn's disease or ulcerative colitis. The diagnosis can be difficult to make because symptoms of Crohn's disease are similar to those of inflammatory bowel disease. ${ }^{2,3}$ Useful diagnostic tools are colonoscopy ${ }^{2,4}$ with biopsy, scintigraphy, and abdominal echography. More complex examinations, such as computerized axial tomography and nuclear magnetic resonance, are needed in the event of complications. The most common diagnostic symptom is abdominal pain associated with diarrhea and, sometimes, fever. Pain is localized to the umbilicus on the right side of the abdomen and often manifests after meals. Other symptoms depend on location of the disease, and include inflammation around the anus and/or the perianal region; this localization is rather frequent, and leads to various complications like fistulae (abnormal connections between the intestine and the skin surface, by the anus) or abscesses. Complications associated with Crohn's disease affect approximately $10 \%-20 \%$ of individuals, whereas the remaining $80 \%-90 \%$ respond successfully to treatment. Complications may be intestinal (stenoses, perforations, abdominal abscesses and fistulae, and carcinoma of the small bowel or colon) or systemic in that they can affect extraintestinal sites leading to inflammation of the joints (eg, arthritis, arthralgia) eye inflammation (uveitis), skin conditions, kidney stones, gallstones, and nutritional problems (protein/vitamin deficiency, ${ }^{5}$ asthenia, anorexia, and weight loss).

All medical conditions have negative consequences for the patient, their family, and society. The patient experiences pain and suffering (with consequences on quality of life), has a shorter life expectancy, and increased expenses. ${ }^{6}$ Families have to cope with emotional stress and financial loss. Society deals with the emotional burden on the family caused by the disease, in addition to providing for the cost of resource utilization for health care interventions and loss of productivity due to morbidity, disability, and premature death. ${ }^{7}$ Evaluation of total direct, indirect, and intangible costs of a disease is known as a cost-of-illness analysis. Such studies measure and evaluate the resources used to manage a disease and quantify the associated costs, thus serving as a tool for assessing the economic consequences of a condition on the economic system. ${ }^{8}$ Direct costs refer to the resources used to prevent and treat a disease, and associated issues such as medications, physicians, nursing personnel, laboratory monitoring, hospitalizations, and medical devices, as well as the costs of transportation to or from the hospital, special diets, and clothing. Indirect costs are due to loss of productivity of the patient or their caregivers because of the disease (eg, following hospitalization or because of visits). Intangible costs derive from the effects of the disease on patient and/or caregiver quality of life. The literature ${ }^{9-13}$ suggests that the annual cost of Crohn's disease is mainly due to hospitalizations, whereas medications account for only $7 \%-10 \%$ of the total annual cost for treating patients. Furthermore, the condition has a strong impact on quality of life. It is estimated that the total annual direct cost of Crohn's disease in the United States is $1-1.2$ billion dollars. ${ }^{13-15}$ Individuals with Crohn's disease experience considerable chronic morbidity and require important interventions. When this study was set up, knowledge about the direct, indirect, and intangible costs associated with Crohn's disease was incomplete and scanty, especially in Italy. Our aim was to evaluate resource consumption due to Crohn's disease in Italy and the effects of this condition on quality of life.

\section{Materials and methods \\ Design}

This was an observational prospective study designed by the COSMO Study Group to evaluate direct and indirect costs and quality of life in patients with Crohn's disease in Italy from the perspectives of the National Health System and society. The primary objective of this study was to evaluate the cost of illness and quality of life of individuals with Crohn's disease in the active phase and with a Crohn's Disease Activity Index (CDAI) score $\geq 150$ despite pharmacologic treatment, or with active fistulating disease, diagnosed at least 6 months earlier, and confirmed by x-rays, endoscopy, or other diagnostic examination. The key secondary study objectives were to give an indication of the various cost components paid by the National Health System and society for the management of individuals with Crohn's disease and to provide an indication of the likely quality of life changes for individuals with Crohn's disease relative to the different pharmacologic treatments.

\section{Recruitment}

The study consisted of four visits made every 6 months during a follow-up period of 18 months. It was anticipated that approximately 25 centers would enroll approximately 10-40 subjects each on a consecutive basis. The study started on September 1, 2006 and was completed on April 12, 2010. The target number of subjects who would be eligible for enrolment into this study was about 245 . A total of 162 subjects (67\%) completed the study, while 83 subjects (33\%) discontinued early. Reasons for discontinuation were: subject did not wish to continue ( $\mathrm{n}=55)$; loss to follow-up $(\mathrm{n}=2)$; failure to return for follow-up visits $(n=18)$; serious adverse events $(n=3)$; 


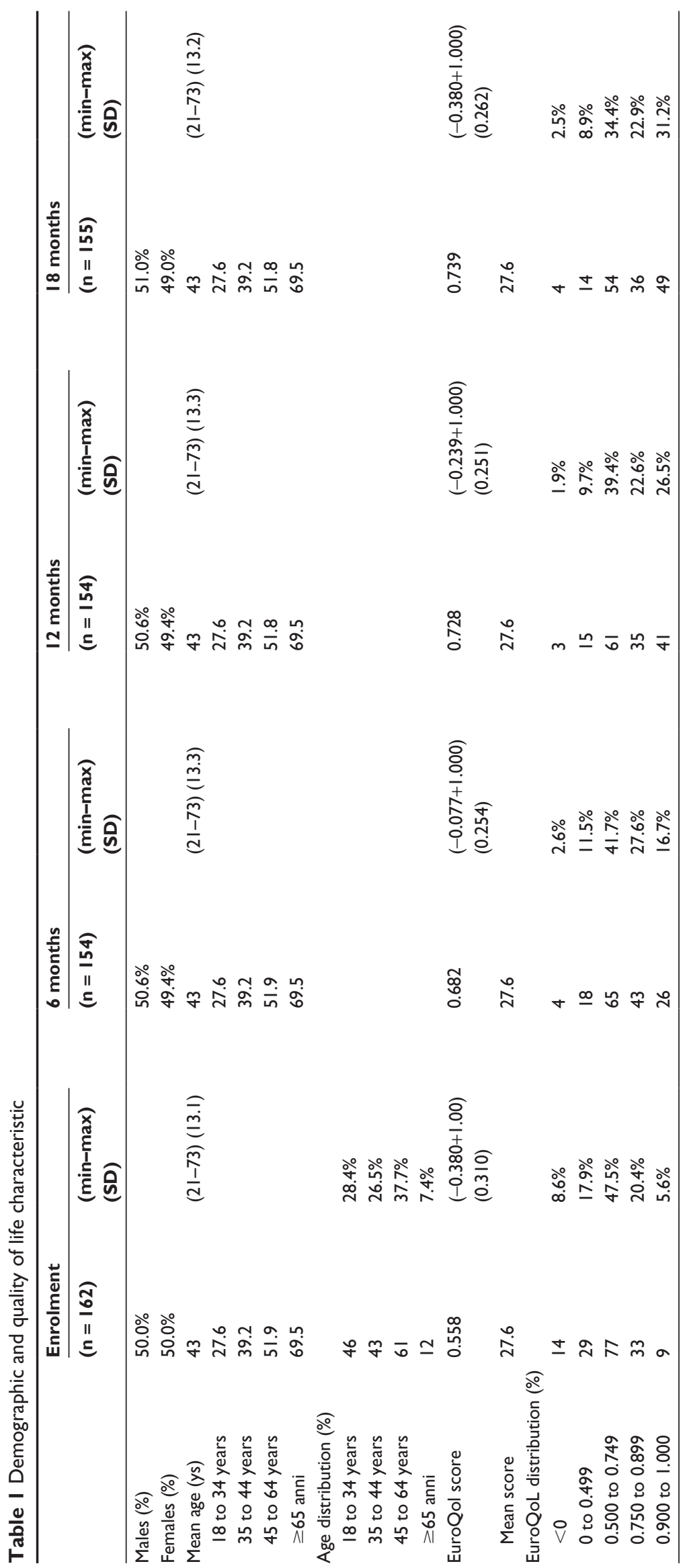


other medical event $(n=29)$; and unspecified reasons $(n=3)$. Subjects who withdrew from the study prematurely were not included in the pharmacoeconomic analysis.

All prior medication taken by the subject within 6 months of starting the study and all concomitant therapy taken during the study were recorded on the case report form. The identity of the therapy, the dose, route, and regimen, the dates started and stopped (or notation of "continuing" if that was the case), and the reason for use were recorded. The study was approved by the relevant local ethical committees, and Declaration of Helsinki protocols were followed. Written informed consent was obtained from all participants.

\section{Inclusion and exclusion criteria}

A subject was eligible for participation in the study based on the following inclusion criteria:

- Age 18-70 years

- Crohn's disease in the active phase with a CDAI score $\geq 150$ despite pharmacologic treatment, or with active fistulating disease

- Crohn's disease diagnosed within at least 6 months of study entry and confirmed by x-rays, endoscopy, or other diagnostic examination

- Provision of informed consent

- Ability to understand the aims of the study and to answer all items on the questionnaire.

A subject was excluded from participation in the study based on the following exclusion criteria:

- Unreliability as to questionnaire completion, eg, past or current abuse of drugs or alcohol, or serious concomitant neurologic and/or psychiatric conditions

- Concomitant diseases that may interfere with the costs of Crohn's disease or its complications, including serious infections (eg, tuberculosis in the active phase), organ transplantation, malignancy, human immunodeficiency virus infection, or uncontrolled renal, cardiac, hepatic, or endocrine disease

- Subjects currently enrolled in another clinical study.

\section{Direct costs}

Direct health care costs were related to physician visits, specialist visits, drug treatment and infusions, diagnostic examinations, laboratory tests, emergency room attendances, and hospitalization. ${ }^{16}$ Hospitalization costs were evaluated on the basis of the national DRG system available from the Italian Ministry of Health. ${ }^{17}$ Specialist medical examinations, laboratory tests, diagnostic procedures, and phototherapy sessions were based on the 2010 National Tariff Nomenclator. ${ }^{18}$ Health care services provided by the private sector and other private costs were evaluated according to the actual expenses incurred by patients. All pharmacologic therapies (topical, systemic, biologics, multiple) were considered in the questionnaire. Alternative treatments were also assessed. To assess the costs of prescribed pharmacologic therapies, units of consumed resources were multiplied by the prices reported in the official Italian price list, ${ }^{19}$ taking into consideration the dosage and duration of treatment. The costs of nonprescription topical medications and alternative treatments were determined by averaging the costs of the most representative drugs recorded in the patient notebooks, based on the official retail price list. Nonhealth care costs related to transport of patients and their relatives, home assistance by volunteers or relatives, and home assistance by others were evaluated according to the actual expenses incurred by patients.

\section{Indirect costs}

The human capital approach was used to estimate productivity loss due to Crohn's disease. ${ }^{8,16}$ Travel costs were not collected. Indirect costs included the value of lost production due to leaving work earlier than usual, sick leave, and loss of leisure time for nonemployees during the study. Patients' time off work (lost working days, permanent reduction or loss of work activities) was measured in terms of salary evaluation, with the assumption that income reflects productivity. The monetary value of one lost working day for patients was calculated to be $€ 98.44$, equal to the gross domestic product per capita per day. ${ }^{20}$ National income data were subsequently updated

Table 2 Health care resource use per patient by observation period and type of resource used

\begin{tabular}{|c|c|c|c|c|c|c|c|c|}
\hline & \multicolumn{2}{|c|}{ Enrolment } & \multicolumn{2}{|l|}{6 months } & \multicolumn{2}{|c|}{12 months } & \multicolumn{2}{|c|}{18 months } \\
\hline & $(n=162)$ & $\begin{array}{l}(\min -\max ) \\
(\mathrm{SD})\end{array}$ & $(n=154)$ & $\begin{array}{l}\text { (min-max) } \\
\text { (SD) }\end{array}$ & $(n=154)$ & $\begin{array}{l}(\min -\max ) \\
(\mathrm{SD})\end{array}$ & $(n=155)$ & $\begin{array}{l}(\min -\max ) \\
\text { (SD) }\end{array}$ \\
\hline \multicolumn{9}{|l|}{ Number of } \\
\hline Physician visits & 5.0 & $(0-30)(6.24)$ & 3.5 & $(0-30)(5.18)$ & 3.1 & $(0-30)(4.44)$ & 2.6 & $(0-25)(3.45)$ \\
\hline Specialist visits & 3.4 & $(0-16)(2.70)$ & 2.2 & $(0-15)(2.62)$ & 2.2 & $(0-15)(2.47)$ & 2.3 & $(0-10)(2.24)$ \\
\hline Diagnostic examinations & 1.93 & $(0-12)(2.10)$ & 0.78 & $(0-5)(1.10)$ & 0.73 & $(0-6)(1.14)$ & 0.68 & $(0-5)(1.13)$ \\
\hline Laboratory tests & 0.97 & $(0-1)(0.174)$ & 0.96 & $(0-1)(0.194)$ & 0.94 & $(0-1)(0.235)$ & 0.99 & $(0-1)(0.234)$ \\
\hline Emergency room & 0.93 & $(0-19)(2.29)$ & 0.11 & $(0-6)(0.662)$ & 0.21 & $(0-8)(0.975)$ & 0.12 & $(0-6)(0.693)$ \\
\hline
\end{tabular}

Abbreviation: SD, standard deviation. 


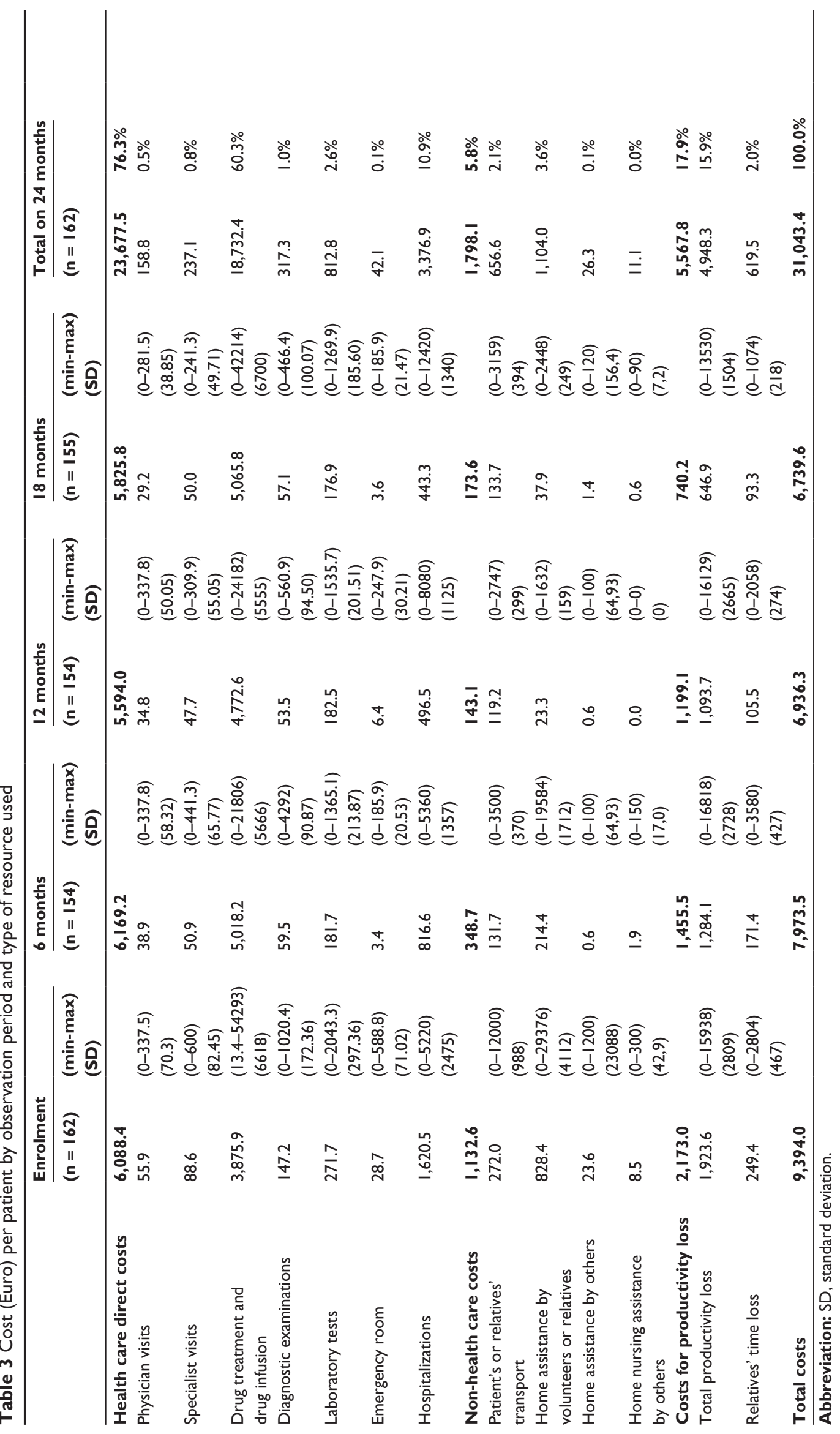


to 2011 according to official inflation rates, and represented a mean value for all of Italy. The analysis was done from both societal and National Health Service perspectives. All costs are expressed in Euros and were updated to 2011 values according to official inflation rates. ${ }^{21}$

\section{Quality of life}

In order to assess quality of life in its broadest sense, patients were asked to complete the EuroQoL ${ }^{22}$ questionnaire (EQ-5D ${ }^{\mathrm{TM}}$ ) which is a standardized instrument for use as a measure of health outcome. Applicable to a wide range of health conditions and treatments, it provides a simple descriptive profile and a single index value for health status. ${ }^{23}$ The EQ-5D questionnaire considers five attributes of quality of life evaluation, ie, mobility, self-care, usual activity, pain/ discomfort, and anxiety/depression. ${ }^{24-26}$ Each attribute has three levels, ie, no problems, some problems, or major problems, thus defining 243 possible health states, to which has been added "unconscious" and "dead", for a total of 245. The scores fall on the 0.0 (dead) to 1.0 (perfect health) value scale. ${ }^{26,27}$

\section{Statistical analysis}

All variables were analyzed using descriptive statistics, ie, mean, standard deviation, median, maximum, and minimum values for continuous variables, and frequency distribution for categorical variables. Results are reported as a whole and separately for each gender and age group. Specifically, variables considered were demographic characteristics, resource use, other cost parameters, and changes in quality of life. ${ }^{16}$ The economic analysis was based on the subjects who completed the 18-month follow-up period in this study.

\section{Results}

Table 1 shows the main sociodemographic and quality of life characteristics. The mean age of the 162 patients $(50 \%$ males) was 43 years. At recruitment, the EuroQol score was 0.558 , as shown in Table 1 . Treatment patterns at baseline (enrolment) and during the observation period are shown in Table 2. Health care resource consumption per patient declined during the observation period.

The consumption of medical services and medication at enrolment and during the period of observation is shown in Table 3 and Figure 1. The mean total cost (direct and indirect) per patient was $€ 31,043.40$ during the 24 months of observation. Direct costs accounted for $76.3 \%$ of the total estimated disease costs for Crohn's disease. The most significant direct costs pertained to drug treatment $(60.3 \%)$ followed by hospitalization $(10.9 \%)$ and laboratory examinations $(2.6 \%)$. Other components of direct cost had a marginal impact on direct costs. Costs related to loss of productivity amounted to $€ 5567.80$, accounting for $17.9 \%$ of total costs (Figure 1).

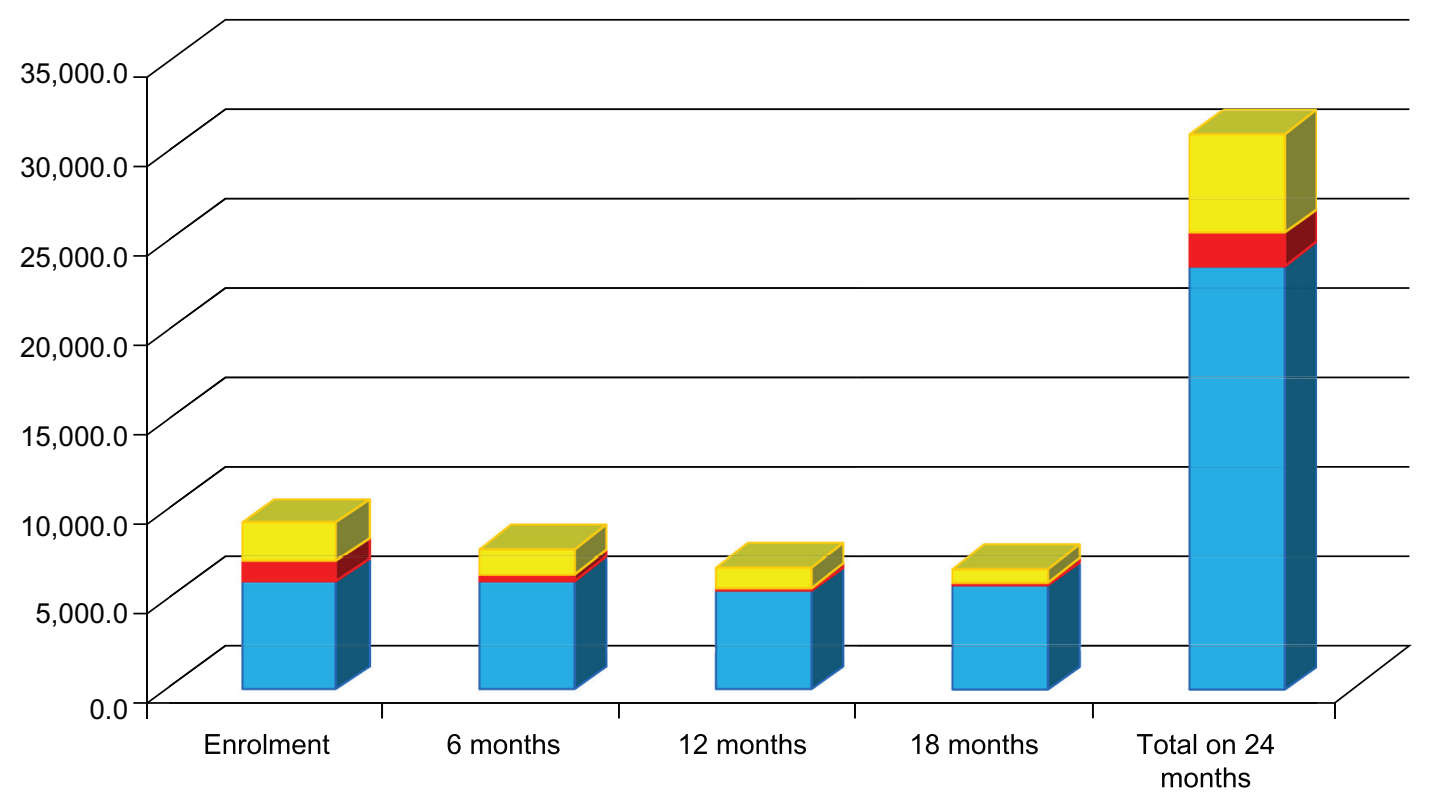

$\square$ Heart care direct costs

Non-health care costs

Costs for productivity loss

Figure I Cost (Euro) per patient by observation period and type of resource used. 
The total cost was higher for males (Table 4), with the cost difference between males and females being mainly due to indirect costs, although the difference $(+3 \%)$ was not statistically significant. We did not find any cost difference according to age group. Societal costs during the first period of the study were higher compared with costs in the last period of the study (Tables 3 and 4).

Quality of life as measured with the EQ-5D was initially 0.558 , and then increased to 0.739 , with a mean value of 0.677 during the study (Table 1). However, cost seemed to be strongly correlated with decreased quality of life (Table 5); the mean health care and societal costs for subjects with a quality of life of $0-0.499$ was $€ 6179$ higher than that of subjects with a quality of life of $0.50-1.00$. Expenses incurred for Crohn's disease treatment were significantly higher for patients with poorer quality of life than for patients with better quality of life (Table 5). Therefore, an increase in drug treatment improved quality of life and markedly reduced hospitalization costs.

\section{Discussion}

Crohn's disease may have a profound impact on an affected person's quality of life and a substantial economic impact for both patients and the health care system. ${ }^{28}$ In spite of this, only a few studies have presented an overall picture of the costs of care for patients with Crohn's disease. ${ }^{9-12,28}$ This also applies to Italy, where little is known about the epidemiology or economics of Crohn's disease. This national multicenter prospective study on the cost of Crohn's disease in Italy was performed using a bottom-up approach in patients during the active phase of the illness with a CDAI score $\geq 150$. Evaluation of the total direct, indirect, and intangible costs of a disease is known as cost-of-illness analysis. Such studies measure and evaluate the resources used to manage a disease and quantify the associated costs, thus serving as a tool for assessing the economic consequences of a disease.

The burden of Crohn's disease per subject in Italy was assessed to be approximately $€ 11,838$ (including only direct costs) to $€ 15,521$ per year (including direct cost and productivity loss). Direct costs represented $76 \%$ of the total costs, and nonhealth care costs and productivity loss accounted for $24 \%$. We did not find differences in cost between males and females or according to age group. Patients over 65 years comprised only $12 \%$ of the total sample, which has a mean age of 43 years. Loss of production was calculated overall for patients who were still working in active employment. Societal costs during the early months of the study were higher compared with costs in the final months of the study.

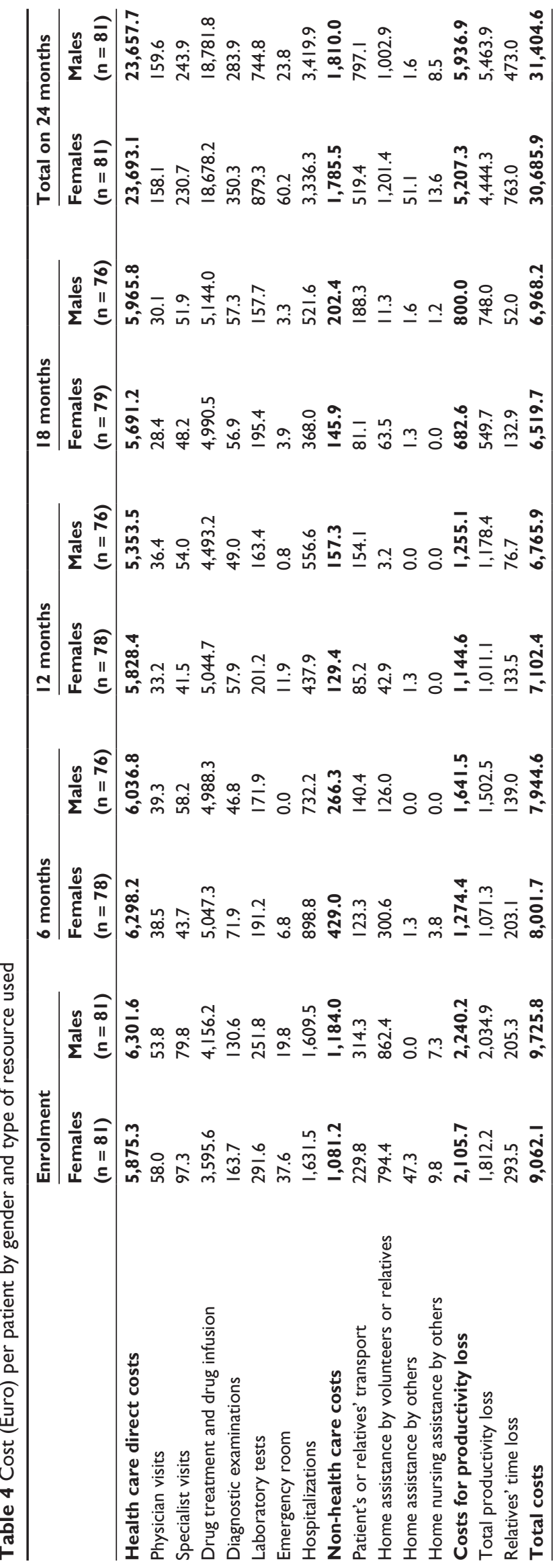


Table 5 Cost (Euro) per patient by EuroQoL score and type of resource used

\begin{tabular}{|c|c|c|c|c|c|c|c|c|c|c|}
\hline & \multicolumn{5}{|c|}{ Enrolment } & \multicolumn{5}{|c|}{6 months } \\
\hline & $\begin{array}{l}<0 \\
(n=14)\end{array}$ & $\begin{array}{l}0 \text { to } \\
0.499 \\
(n=29)\end{array}$ & $\begin{array}{l}0.500 \text { to } \\
0.749 \\
(n=77)\end{array}$ & $\begin{array}{l}0.750 \text { to } \\
0.899 \\
(n=33)\end{array}$ & $\begin{array}{l}0.900 \text { to } \\
1.000 \\
(n=9)\end{array}$ & $\begin{array}{l}<0 \\
(n=4)\end{array}$ & $\begin{array}{l}0 \text { to } \\
0.499 \\
(n=18)\end{array}$ & $\begin{array}{l}0.500 \text { to } \\
0.749 \\
(n=65)\end{array}$ & $\begin{array}{l}0.750 \text { to } \\
0.899 \\
(n=43)\end{array}$ & $\begin{array}{l}0.900 \text { to } \\
1.000 \\
(n=26)\end{array}$ \\
\hline Health care direct costs & $6,856.9$ & $7,130.9$ & $6,265.0$ & $4,6 I I .4$ & $5,460.4$ & $9,417.4$ & $8,322.9$ & $6,875.7$ & $4,946.4$ & $4,587.1$ \\
\hline Physician visits & 74.0 & 71.4 & 45.9 & 63.8 & 28.8 & 45.0 & 40.0 & 48.7 & 25.7 & 32.5 \\
\hline Specialist visits & 148.3 & 89.6 & 84.3 & 84.9 & 32.1 & 67.1 & 49.2 & 54.5 & 40.7 & 56.4 \\
\hline $\begin{array}{l}\text { Drug treatment } \\
\text { and drug infusion }\end{array}$ & $3,962.4$ & $4,503.3$ & $3,963.9$ & $2,939.4$ & $4,793.8$ & $9,036.9$ & $6,648.6$ & $5,583.3$ & $4,220.4$ & $3,362.8$ \\
\hline Diagnostic examinations & 178.9 & 171.2 & 139.2 & I56.I & 29.6 & 69.7 & 57.2 & 71.0 & 42.8 & 60.1 \\
\hline Laboratory tests & 418.4 & 323.1 & 245.8 & 218.2 & 258.4 & 152.2 & 147.7 & 195.6 & 177.3 & 180.3 \\
\hline Emergency room & 86.3 & 47.0 & 19.7 & 15.0 & 0.0 & 46.5 & 6.9 & 3.3 & 0.0 & 0.0 \\
\hline Hospitalizations & I,988.6 & ।,925.2 & I,766.I & I, 133.9 & 317.8 & 0.0 & I,373.3 & 919.2 & 439.5 & 895.0 \\
\hline Non-health care costs & $3,983.6$ & I,373.2 & 920.5 & 404.0 & 185.9 & $4,970.6$ & 616.5 & 213.2 & 147.0 & 102.8 \\
\hline $\begin{array}{l}\text { Patient's or relatives' } \\
\text { transport }\end{array}$ & $1,008.5$ & 200.2 & 212.1 & 177.7 & 185.9 & 12.1 & 73.3 & 156.9 & 147.0 & 97.0 \\
\hline $\begin{array}{l}\text { Home assistance by } \\
\text { volunteers or relatives }\end{array}$ & $2,885.1$ & $1,141.0$ & 672.4 & 220.9 & 0.0 & $4,896.0$ & 543.2 & 56.3 & 0.0 & 0.0 \\
\hline Home assistance by others & 85.7 & 16.6 & 27.3 & 0.0 & 0.0 & 25.0 & 0.0 & 0.0 & 0.0 & 0.0 \\
\hline $\begin{array}{l}\text { Home nursing assistance by } \\
\text { others }\end{array}$ & 4.3 & 15.5 & 8.8 & 5.5 & 0.0 & 37.5 & 0.0 & 0.0 & 0.0 & 5.8 \\
\hline Costs for productivity loss & $4,975.4$ & $2,684.6$ & I,777.3 & I,784.3 & 556.5 & $4,233.4$ & I,777.0 & $\mathrm{I}, \mathrm{I} 22.4$ & $1,267.7$ & $\mathrm{I}, \mathbf{8 5 8 . 0}$ \\
\hline Total productivity loss & $4,489.6$ & $2,347.7$ & $1,601.8$ & I,509.5 & 457.0 & $4,158.8$ & $\mathrm{I}, 545.8$ & 959.7 & $\mathrm{I}, 167.5$ & $\mathrm{I}, 586.7$ \\
\hline Relatives' time loss & 485.8 & 336.9 & 175.5 & 274.8 & 99.4 & 74.6 & 231.2 & 162.7 & 100.3 & 271.4 \\
\hline Total costs & $15,8 \mid 6.0$ & II, I 88.8 & $8,962.8$ & $6,799.7$ & $6,202.8$ & $18,62 \mid .4$ & $10,716.5$ & $8,211.3$ & $6,361.1$ & $6,548.0$ \\
\hline
\end{tabular}

Quality of life as measured by the EQ-5D was 0.558 initially, increasing to 0.739 , with a mean value of 0.677 during the study. Drug treatment was the most important cost item $(60 \%)$, followed by the cost of hospitalization $(10 \%)$. However, cost seemed to be strongly correlated with diminished quality of life; at enrolment, the health care and societal costs for subjects with a quality of life of $0-0.499$ was $84 \%$ higher than that for subjects with a quality of life of $0.50-1.00$. It should be pointed out that drugs were the most significant item contributing to total cost, with drug costs increasing in proportion to decreasing quality of life and decreasing costs of hospitalization. This relationship could be considered from another point of view, ie, treatment ameliorates the disease but at the cost of side effects which worsen quality of life. However, further research is needed to identify the exact reasons for this association.

The results of this study provide descriptive data on patterns of resource use and show that the more severe the Crohn's disease, the higher the direct and indirect costs of its management, and that the direct costs are higher than the indirect costs. Quality of life in Crohn's disease is poor when compared with that of the general population and for certain other common chronic diseases, eg, diabetes, in the Italian scenario. ${ }^{29}$ Our results appear to be in line with those of the international cost-of-illness studies performed in other countries. ${ }^{9-12,28}$

There are some limitations to this study and the results are likely to underestimate total disease costs for various reasons. The first possible limitation concerns extrapolation of 6-months expenses among the whole period of the study (18 months), because patients' expenses, especially in those with severe disease, are related both to the contextual conditions and to the commonly and routinely used items, whose costs can be underestimate in a short period of analysis. Use of the human capital approach to calculate indirect costs in the form of overall productivity losses can discriminate against people with no market value, such as the unemployed, retired people, and housewives. On the other side, this study included a complete evaluation of comorbidities and reduction of productivity by families and caregivers. These expenses might represent an important cost driver for the total burden of disease. ${ }^{12,28}$

Increasing use of innovative treatments for Crohn's disease has been noted recently, and with the advent of new biologic agents (infliximab, adalimumab, certolizumab), the costs of treating Crohn's disease will be even higher. ${ }^{30,31}$ However, prescribing these new albeit costly drugs could be associated with less loss of productivity and a reduction in diagnostic procedures and hospitalization, with great benefit from the societal point of view. ${ }^{32}$ These investments in innovative 


\begin{tabular}{|c|c|c|c|c|c|c|c|c|c|}
\hline \multicolumn{5}{|c|}{12 months } & \multicolumn{5}{|c|}{18 months } \\
\hline $\begin{array}{l}<0 \\
(n=3)\end{array}$ & $\begin{array}{l}0 \text { to } \\
0.499 \\
(n=15)\end{array}$ & $\begin{array}{l}0.500 \text { to } \\
0.749 \\
(n=6 I)\end{array}$ & $\begin{array}{l}0.750 \text { to } \\
0.899 \\
(n=35)\end{array}$ & $\begin{array}{l}0.900 \text { to } \\
1.000 \\
(n=4 I)\end{array}$ & $\begin{array}{l}<0 \\
(n=4)\end{array}$ & $\begin{array}{l}0 \text { to } \\
0.499 \\
(n=14)\end{array}$ & $\begin{array}{l}0.500 \text { to } \\
0.749 \\
(n=54)\end{array}$ & $\begin{array}{l}0.750 \text { to } \\
0.899 \\
(n=36)\end{array}$ & $\begin{array}{l}0.900 \text { to } \\
1.000 \\
(n=49)\end{array}$ \\
\hline $6,854.0$ & $7,151.1$ & $6,589.6$ & $4,555.9$ & $4,207.5$ & $5,222.2$ & $7,389.1$ & $6,139.6$ & $5,987.3$ & $4,988.8$ \\
\hline 33.8 & 64.6 & 39.1 & 33.5 & 18.1 & 42.2 & 40.2 & 33.2 & 31.9 & 17.5 \\
\hline 68.9 & 59.0 & 54.7 & 40.7 & 36.3 & 67.1 & 58.3 & 57.6 & 50.5 & 35.3 \\
\hline $5,562.6$ & $6,264.6$ & $5,518.0$ & $3,770.3$ & $3,804.2$ & $4,114.4$ & $5,395.4$ & $5,280.9$ & $5,505.0$ & $4,525.1$ \\
\hline 128.4 & 135.6 & 62.4 & 32.6 & 21.4 & 83.9 & 103.4 & 73.4 & 41.1 & 33.0 \\
\hline 253.6 & 223.0 & 195.9 & 208.3 & 117.5 & 163.0 & 227.6 & 182.3 & 184.2 & | 47.2 \\
\hline 0.0 & 8.3 & 10.2 & 7.1 & 0.0 & 46.5 & 17.7 & 0.0 & 3.4 & 0.0 \\
\hline 806.7 & 396.0 & 709.3 & 463.4 & 210.0 & 705.0 & I,546.4 & 512.2 & 171.1 & 230.6 \\
\hline 12.7 & 263.0 & | 47.3 & 151.9 & 94.6 & 623.9 & 204.6 & 164.9 & 175.9 & 130.3 \\
\hline 12.7 & 241.2 & 114.5 & 115.7 & 92.2 & 11.9 & 72.4 & 145.9 & 152.1 & 130.3 \\
\hline 0.0 & 21.8 & 32.8 & 36.1 & 0.0 & 612.0 & 116.6 & 17.4 & 23.8 & 0.0 \\
\hline 0.0 & 0.0 & 0.0 & 0.0 & 2.4 & 0.0 & 15.7 & 0.0 & 0.0 & 0.0 \\
\hline 0.0 & 0.0 & 0.0 & 0.0 & 0.0 & 0.0 & 0.0 & 1.7 & 0.0 & 0.0 \\
\hline $5,464.3$ & 906.1 & $1,650.9$ & $1,200.7$ & 303.9 & 157.2 & $2,485.2$ & 804.7 & 535.1 & 346.7 \\
\hline $5,464.3$ & 801.7 & I,503.4 & I,090.7 & 259.1 & 157.2 & $2,340.3$ & 693.9 & 450.1 & 277.0 \\
\hline 0.0 & 104.4 & 147.5 & 110.0 & 44.7 & 0.0 & 144.9 & 110.8 & 84.9 & 69.7 \\
\hline $12,330.9$ & $8,320.1$ & $8,387.8$ & $5,908.4$ & $4,606.0$ & $6,003.4$ & $10,079.0$ & $7,109.2$ & $6,698.3$ & $5,465.8$ \\
\hline
\end{tabular}

treatments for Crohn's disease might also provide future benefits, due to avoidance of recurrent problems, improved compliance, and better quality of life. ${ }^{33,34}$ Adequate analysis of outcomes and costs, as performed for the biologics in current use, should be assessed in terms of their incremental cost-effectiveness ratio. ${ }^{35}$

In conclusion, this project is the first complete study of the burden of Crohn's disease in Italy. Crohn's disease is an important economic burden in Italy, both to society and the National Health System. ${ }^{36}$ This study provides evidence of an association between severity of Crohn's disease and cost of illness, as well as basic data for further decision-making, dealing especially with economic assessment of innovative therapies for moderate and severe plaque psoriasis. Further data on outcomes need to be collected over a longer time frame.

\section{Acknowledgments}

This study was financially supported by Merck Sharp and Dohme, SpA, Rome, Italy. The findings are presented here on behalf of the COSMO Study Group: A Angelo, Ospedale Casa Sollievo della Sofferenza, SG Rotondo, Foggia; Benedetti Antonio, Ospedali Riuniti di Ancona; Bianchi Porro Gabriele, AO, Luigi Sacco, Milano; Koch Maurizio, Ospedale San Filippo Neri, Roma; Doldo Patrizia, AO Mater
Domini, Catanzaro; Arrigoni Arrigo, Presidio Ospedaliero S Giovanni Antica Sede, Torino; Francavilla Antonio e Di Leo Alfredo, Policlinico Consorziale, Bari; Fries Walter, AO Policlinico Universitario "G Martino", Messina; Terruzzi Vittorio, Ospedale Valduce, Como; Kohn Anna, Ospedale S Camillo Forlanini, Roma; Valpiani Daniela, Ospedale Morgagni Pierantoni, Forlì, Italy.

\section{Disclosure}

The authors report no conflicts of interest in this work.

\section{References}

1. Achkar JP, Barmada MM, Duerr RH. Perinuclear neutrophil antibodies are not markers for genetic susceptibility or indicators of genetic heterogeneity in familial ulcerative colitis. Am J Gastroenterol. 2002;97: 2343-2349.

2. Lashner BA. Colorectal cancer surveillance for patients with inflammatory bowel disease. Gastrointest Endosc Clin N Am. 2002;12: 135-143.

3. Wolf JM, Lashner BA. Inflammatory bowel disease: sorting out the options. Cleve Clinic J Med. 2002;69:621-631.

4. Mattar MC, Lough D, Pishvaian MJ, Charabaty A. Current management of inflammatory bowel disease and colorectal cancer. Gastrointest Cancer Res. 2011;4:53-61.

5. Peura D, Fennerty B, Lashner B. Osteoporosis for the Gastroenterologist. Hertfordshire, UK: Strategic Consultants International; 2002.

6. Lucioni C. La qualità della vita nella valutazione economica. Cronache Farmaceutiche, Anno XXXVII, N. 6, 1994. Italian.

7. Hodgson T. The state of the art of cost of illness estimates. Adv Health Econ Health Serv Res. 1983;4:129-164. 
8. Drummond MF, O'Brien BJ, Stoddart GL, et al. Methods for the Economic Evaluation of Health Care Programmes. 3rd ed. New York, NY: Oxford University Press; 2006.

9. Blomqvist P, Ekbom A. Inflammatory bowel diseases: health care and costs in Sweden in 1994. Scand J Gastroenterol. 1997;32: 1134-1139.

10. Bernstein CN, Papineau N, Zajaczkowki J, et al. Direct hospital costs for patients with inflammatory bowel disease in a Canadian tertiary care university hospital. Am J Gastroenterol. 2000;95:677-683.

11. Cohen RD, Larson LR, Roth JM, Becker RV, Mummert LL. The cost of hospitalization in Crohn's disease. Am J Gastroenterol. 2000;95: 524-530.

12. Silverstein D, Loftus EV, Sandborn WJ, et al. Clinical course and costs of care for Chron's disease: Markov model analysis of a populationbased cohort. Gastroenterology. 1999;117:49-57.

13. Feagan BG. Review article: economic issues in Crohn's disease assessing the effects of new treatments on health-related quality of life. Aliment Pharmacol Ther. 1999;13 Suppl 4:29-37.

14. Borgaonkar MR, Irvine JR. Quality of life measurement in gastrointestinal and liver disorders. Gut. 2000;47:444-454.

15. Lichtenstein GR, Bala M, Han C, DeWoody K, Schaible T. Infliximab improves quality of life in patients with Crohn's disease. Inflamm Bowel Dis. 2002;8:237-243.

16. Italian Health Economics Association. Guidelines proposal on how to conduct economic evaluation studies of health programs. Pharmacoeconomics - Italian Research Articles. 2009;11:83-93. Italian.

17. Health Ministry, DRG Tariff. TUC Tariffa Unica Convenzionale, Conferenza delle Regioni e delle Province Autonome, compensazione interregionale della mobilità sanitaria Testo Unico, Versione in vigore per le attività dell'anno 2010. Rome, May 5, 2011. Italian.

18. Health Ministry. 2010 National Tariff Nomenclator. Nomenclatore delle Prestazioni di assistenza specialistica ambulatoriale, Ministero della Salute, 2011. Italian.

19. Italian Medicines Agency. Negoziazione e rimborsabilità. Italian. Available from: http://www.agenziafarmaco.gov.it/it/content/ negoziazione-e-rimborsabilit\%C3\%A0. Accessed September 23, 2011.

20. Banca d'Italia. La ricchezza delle famiglie italiane - anno 2010, n. 64-2011 14-12-2011. Italian. Available from: http://www.bancaditalia. it/statistiche/stat_mon_cred_fin. Accessed April 21, 2012.

21. ISTAT Istituto Nazionale di Statistica. Nation Institute of Statistics. Italian. Available from: http://seriestoriche.istat.it/index.php?id=7\& user_100ind_pi1[id_pagina] $=70 \& \mathrm{cHash}=468 \mathrm{e} 508 \mathrm{f} 3 \mathrm{~b} 1982 \mathrm{a} 1 \mathrm{c} 919 \mathrm{~b} 74$ 0b8f13d66. Accessed April 21, 2012.

22. EQ-5D ${ }^{\mathrm{TM}}$ [homepage on the Internet]. Rotterdam, The Netherlands: EuroQol Group. Available from: http://www.euroqol.org. Accessed April 21, 2012.
23. [No authors listed]. EuroQoL: a new facility for the measurement of health-related quality of life. Health Policy. 1990;16:199-208.

24. Essink-Bot ML, Stouthard ME, Bonsel GJ. Generalizability of valuations on health states collected with the EuroQolc-questionnaire. Health Econ. 1993;2:237-246.

25. Brooks R. EuroQol: the current state of play. Health Policy. 1996;37: 53-72.

26. Kind P. The EuroQol instrument: an index of health-related quality of life. In: Spiker B, editor. Quality of Life and Pharmacoeconomics in Clinical Trials. 2nd ed. Philadelphia, PA: Lippincott-Raven Publishers; 1996.

27. Dolan P, Gudex C, Kind P, et al. A Social Tariff for EuroQol: Results from a UK General Population Survey, Discussion Paper 138. New York, NY: Centre of Health Economics, University of York; 1995.

28. Feagan BG, Vreeland MG, Larson LR, et al. Annual cost of care for Crohn's disease: a payor prospective. Am J Gastroenterol. 2000;95: $1955-1960$

29. Lucioni C, Garancini MP, Massi-Benedetti M, Mazzi S, Serra G. The costs of type 2 diabetes mellitus in Italy: a CODE-2 sub-study. Treat Endocrinol. 2003;2:121-133.

30. Bodger K, Kikuchi T, Hughes D. Cost-effectiveness of biological therapy for Crohn's disease: Markov cohort analyses incorporating United Kingdom patient-level cost data. Aliment Pharmacol Ther. 2009;30:265-274

31. Dretzke J, Edlin R, Round J, et al. A systematic review and economic evaluation of the use of tumour necrosis factor-alpha (TNF- $\alpha$ ) inhibitors, adalimumab and infliximab, for Crohn's disease. Health Technol Assess. 2011;15:1-244.

32. Binion DG, Louis E, Oldenburg B, et al. Effect of adalimumab on work productivity and indirect costs in moderate to severe Crohn's disease: a meta-analysis. Can J Gastroenterol. 2011;25:492-496.

33. Yu AP, Johnson S, Wang ST, et al. Cost utility of adalimumab versus infliximab maintenance therapies in the United States for moderately to severely active Crohn's disease. Pharmacoeconomics. 2009;27:609-621.

34. Loomes DE, Teshima C, Jacobs P, Fedorak RN. Health care resource use and costs in Crohn's disease before and after infliximab therapy. Can J Gastroenterol. 2011;25:497-502.

35. Sprakes MB, Ford AC, Suares NC, et al. Costs of care for Crohn's disease following the introduction of infliximab: a single-centre UK experience. Aliment Pharmacol Ther. 2010;32:1357-1363.

36. Koopmanshap MA. Cost of illness studies: useful for health policy? Pharmacoeconomics. 1998;14:143-148.
ClinicoEconomics and Outcomes Research

\section{Publish your work in this journal}

ClinicoEconomics \& Outcomes Research is an international, peerreviewed open-access journal focusing on Health Technology Assessment, Pharmacoeconomics and Outcomes Research in the areas of diagnosis, medical devices, and clinical, surgical and pharmacological intervention. The economic impact of health policy and health systems

\section{Dovepress}

organization also constitute important areas of coverage. The manuscript management system is completely online and includes a very quick and fair peer-review system, which is all easy to use. Visit http://www.dovepress.com/testimonials.php to read real quotes from published authors. 